\title{
CORRECTION
}

\section{Correction to: COVID-19 research: promising tracks leading to uro-oncology}

\author{
Tamás Fazekas $^{1} \cdot$ Tibor Szarvas $^{1,2} \cdot$ Anita Csizmarik $^{1} \cdot$ Boris Hadaschik $^{2} \cdot$ Péter Nyirády $^{1}$
}

Published online: 20 August 2020

(c) Springer Nature B.V. 2020

\section{Correction to: \\ International Urology and Nephrology \\ (2020) 52:995-997 \\ https://doi.org/10.1007/s11255-020-02490-2}

In the original publication, surname and given names were interchanged for all the authors. The correct names should read as Tamás Fazekas, Tibor Szarvas, Anita Csizmarik, Boris Hadaschik, Péter Nyirády.

Publisher's Note Springer Nature remains neutral with regard to jurisdictional claims in published maps and institutional affiliations.

The original article can be found online at https://doi.org/10.1007/ s11255-020-02490-2.

Péter Nyirády

nyiradyp@gmail.com

1 Department of Urology, Semmelweis University, Budapest, Hungary

2 Department of Urology, Faculty of Medicine, University Duisburg-Essen, Essen, Germany 